\title{
Spinal dermal sinus tract
}

\author{
George A. Alexiou • Neofytos Prodromou
}

Received: 2 October 2009 / Accepted: 20 January 2010 / Published online: 17 February 2010

(C) Springer-Verlag 2010

\section{Dear Editor,}

We read with great interest the recent article by Radmanesh et al. [1] concerning spinal dermal sinus tract (DST) in children. The authors studied 35 children with this rare congenital dysraphism. They reported that infection and
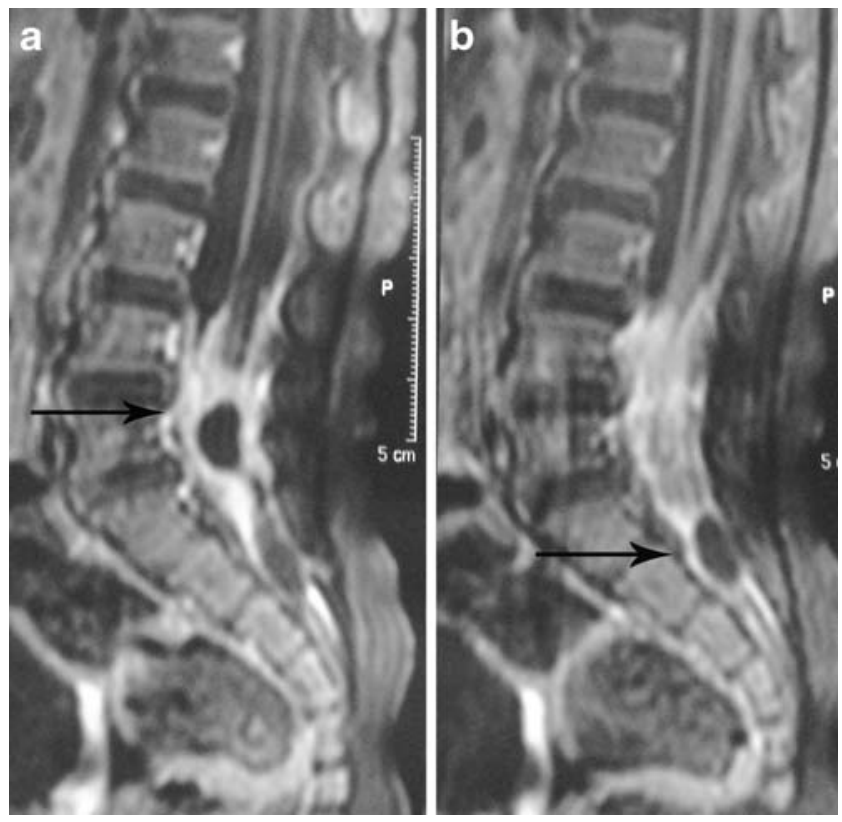

Fig. 1 a, b Sagittal short T1 inversion recovery (STIR) image of a 1year-old boy with an extradural and intradural dermoid tumor along the dermal sinus tract (arrows)

G. A. Alexiou $(\bowtie) \cdot$ N. Prodromou

Department of Neurosurgery, Children's Hospital "Agia Sofia", Aetideon 52, Holargos,

Athens, Attica 11561, Greece

e-mail: alexiougrg@yahoo.gr

e-mail: alexiougr@gmail.com
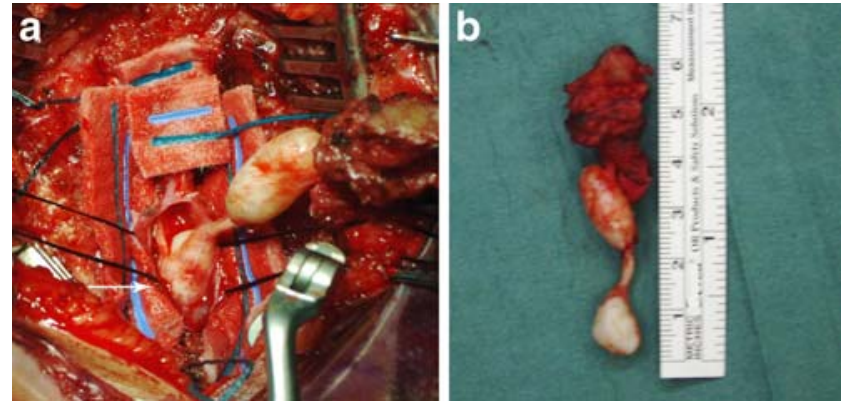

Fig. 2 a Intraoperative findings of the intradural (arrow) and extradural dermoid tumor along the sinus tract. b The dermal sinus tract with the two dermoid tumors

neurological abnormalities were a common finding. The most common radiological finding was tethered cord, and most patients had abnormal findings in urological evaluation. The authors concluded that timely intervention and complete resection is of paramount importance for patient's outcome.

We have recently studied the DSTs that were treated in our institute over the last decade. We encountered one case of DST in the thoracic area and two cases in the lumbar area. All patients presented with meningitis. On radiological evaluation no addition abnormalities were revealed. In two cases, there was an extradural and intradural dermoid tumor along the sinus track (Figs. 1 and 2). Using a microsurgical technique, the DST was removed in all cases. Postoperative all patients were neurologically intact. Timely diagnosis and surgical intervention with intradural exploration is crucial in order to prevent DST's complications.

\section{References}

1. Radmanesh F, Nejat F, El Khashab M (2009) Dermal sinus tract of the spine. Child Nerv Syst, doi:10.1007/s00381-009-0962-z 